Date of completion: 4 December 2008

\title{
Putting the Eco in Ecotoxicology
}

\author{
John Cairns, Jr. \\ Department of Biological Sciences, Virginia Polytechnic Institute and State University, \\ Blacksburg, Virginia 24061, USA
}

\begin{abstract}
You don't ever want a crisis to go to waste. It's an opportunity to do important things you would otherwise avoid. Rahm Emanuel

President-elect Barack Obama's Chief of Staff
\end{abstract}

On November 18, 2008, the Society of Environmental Toxicology and Chemistry (SETAC) honored my life's work by convening a special session at its Annual Meeting in Tampa, Florida, entitled "Putting the Eco in Ecotoxicology." Although I am no longer able to travel and could not attend, this thoughtful action brought tears to my eyes, and the realization that SETAC colleagues remembered my research will keep my spirits high for as long as I live. The co-chairs of the special session, Sean Richards and Mark Hanson, were a pleasure to work with. They requested photographs ${ }^{1}$ that could be used for projection on a screen between presentations during the day's special session. Selecting photographs from a career of 60 years was a mixture of joy and acceptance - joy that I once had brown hair and a 32-inch waist and acceptance that the hair is now white and I have a 44-inch waist.

In 1982, I was honored to receive the SETAC Founder's Award at its $2^{\text {nd }}$ Annual Meeting. I gave a talk as part of the award ceremony entitled "Are Single Species Toxicity Tests Alone Adequate for Estimating Environmental Hazard?" (Cairns 1983). The talk aroused a long period of questions afterward, but no one asked me to return the award. My perspective at that time reflected my personal experience. My research career began as a member of a river survey team from the Academy of Natural Sciences, which studied the effects of pollution upon aquatic communities of the Conestoga River and its tributaries in Pennsylvania. I was responsible for work with the protozoan communities (Cairns 1949), but other team members studied the entire food web from bacteria up to fish. Water chemistry was also a major component of the study. Consequently, the context in which I first studied toxicity was at the systems and community levels. In 1948, when the Conestoga River basin survey was nearly over, the two river survey teams were reduced to one permanent team that began studies of the effects of waste discharges in streams in many locations in North America. Some of these studies (Patrick et al. 1967) continued on a regular seasonal basis for many years, while others were completed only one or more times. However, these studies were baseline (pre-waste discharge) or reactive (i.e., toxic effects studied after they occurred in natural systems). I realized that predictive methods were needed, but I had no idea what they should be.

Then, Dr. W. B. Hart, a strong supporter of the Limnology Department in the Academy of Natural Sciences and a pharmacologist at the Atlantic Refining Company, who had produced a now classic monograph in 1945 (Hart et al. 1945) on toxicity testing using bluegill sunfish, both mentored me in methodology and gave me the equipment that he, Doudoroff, and Greenbank had used to produce the original monograph. For a few years, I carried out tests on industrial wastes and finally acquired enough confidence to publish in the field of toxicity testing (e.g., Cairns 1957, Cairns and Scheier 1957). My research then expanded from fish to three components of the food chain - one species of algae, one invertebrate, and one fish (Cairns et al. 1963). Earlier (Cairns 1956a,b), I had studied the effects of increased temperature on three levels of the food chain, so the basic methodology was already available. However, even though the diatoms were usually most sensitive to toxics, often either the invertebrate or fish was the most sensitive. I faced significant resistance to this finding because this era used "the most sensitive species" and "the most representative species" concepts.

\footnotetext{
${ }^{1}$ My daughter Karen helped select the photographs and my daughter Heather placed them on my website. Valerie Sutherland in the Department of Biological Sciences at Virginia Tech scanned the photographs for digital use, and my editorial assistant Darla Donald typed and edited my brief remarks that were read at the special session.
} 
During this period, I had trouble getting manuscripts published in biological (including ecological) journals because the research was not deemed "suitable." This attitude later changed, especially after the first "Earth Day." For me, a major defining moment was the first "Pellston Workshop" (Cairns et al. 1977), which examined the entire system from both toxicological and chemical standpoints. The workshop was held at the University of Michigan Biological Station after the summer session there. Perhaps the proximity of both aquatic (Douglas Lake) and terrestrial ecosystems was a factor in developing a systems perspective. The Pellston workshops became a series, and in the 1980s were adopted by SETAC, which provided the stability for the workshops that had previously been lacking. In 1981, ecotoxicology received additional academic recognition in the National Research Council book Testing for Effects of Chemicals on Ecosystems (Cairns et al. 1981). About the same time (e.g., Cairns et al. 1979), environmental biomonitoring provided a needed feedback loop from natural systems to laboratory predictive models.

Significant advancements have been made in ecotoxicology since those early days, but the future of Homo sapiens is in doubt, climate change continues (literally fueled by increasing greenhouse gas emissions and positive greenhouse gas feedback loops), peak oil has already occurred, and last, but far from least, ubiquitous toxics abound. All these environmental situations are occurring during a global financial meltdown. Humankind is rapidly creating an alien planet (i.e., inhospitable), but the economy, not the health of the biospheric life support system, remains the primary focus of the world's political leaders and their constituents.

Humankind appears to be suffering from what US President-elect Barack Obama has called an empathy deficit (Lakoff 2008, p. 47). In the context of this commentary, the deficit is evident as a failure to care for the $30+$ million other species with which humans share the planet. Lakoff $(2008$, p. 47$)$ notes: "Caring is not just feeling empathy; it is taking responsibility, acting powerfully and courageously. You have to be strong to care, and to act on that care with success. ... [and on p. 49] Empathy leads to recognizing that unfair and discriminatory treatment is a form of harm requiring government protection." All the ecotoxicological science in the world will not be effective unless humankind has active empathy for natural systems and all the species that inhabit them. In graduate school, I was taught not to mix science and personal values. Early in my professional career, I realized that biophilia should serve as the foundation of my value system. One should always note when values are being discussed and be equally clear about science.

\section{Cognitive Dissonance}

Lakoff $(2008$, p. 70$)$ notes: "the brain mechanism of bioconceptual thought is mutual inhibition, where both worldviews exist in the same brain but are linked to nonoverlapping areas of life." As a consequence, students (and faculty) can party on Saturday night, expressing one set of values, and go to church on Sunday morning, expressing yet another set of values, and have no discomfort in doing so. Similarly, individuals can simultaneously advocate robust economic growth and environmental protection, despite a preponderance of scientific evidence that economic growth is causing massive environmental damage. The economic focus on profit and deregulation and the contradictory focus on accountability for protecting natural systems are incongruent. Despite assertions that humans are apart from the biospheric life support system rather than a part of it, damage to it so that its functions and services change may result in Homo sapiens joining the long list of extinct species.

\section{Framing a Nurturant Metaphor}

If humankind is dependent upon the biospheric life support system, humankind's primary responsibility should be to nurture it and protect its health and integrity. This framework is useful for addressing climate change issues. Earth's biospheric life support system can only assimilate a finite amount of carbon dioxide any excess remains in the atmosphere and causes climate change. An economic model cannot be used to address this problem because the human economy is based on natural capital, which is the basis for all other types of capital. If the biospheric life support system malfunctions badly for humans, they will be driven to extinction and their economic system will cease to exist. However, in the twisted "logic" of the United States in the $21^{\text {st }}$ century, saving the biospheric life support system is voted down if it might have a negative effect on the economy. The human economy is a wholly dependent subset of the biospheric life support system.

\section{The Future of Ecotoxicology}

If ecotoxicologists accept this reasoning, then ecotoxicologists have a responsibility to not only protect global ecosystems but to see that they flourish. This approach means going beyond absence of deleterious effects to ensure that ecosystem functions and integrity are maintained. All outputs (i.e., wastes) from human society can serve as useful inputs to ecological systems. All human outputs (e.g., greenhouse gases) should be treated as toxics if they exceed ecosystem assimilative capacity. Biotic impoverishment (i.e., less species 
diversity) must be eliminated, and habitat loss must be reduced to nearly zero while increasing habitat by means of ecological restoration.

Evolution favors resource partitioning, which means no excessive use of resources by a single species. Mother Nature has a solution to excessive growth - it is called extinction. The list of extinct species far exceeds the list of presently alive species. Many politicians and economists extol perpetual economic growth, and, for a time, this siren song defied increasing evidence that it was unsuitable for a finite planet.

However, the biosphere has been a pulsing system, as evidenced by both exogenous events (e.g., impacts of large objects from outer space) and endogenous events (e.g., food shortages and pandemic diseases). During cataclysmic events, many species may become extinct, but persuasive evidence now indicates that major species extinctions may occur gradually and continually between major catastrophic events. For decades, I believed that sustainable use of the planet was possible for an intelligent species that developed a mutualistic, nurturing, harmonious relationship with the biospheric life support system. I still believe it possible, but not if humankind continues "business as usual." Empowerment of the individual need not have caused a disconnect between humankind and the biospheric life support system, but it appears to have done so.

\section{Conclusions}

If humankind wishes to avoid extinction, it must develop a nurturing relationship with the biospheric life support system. Ideally, all humans should participate in this endeavor. Ecotoxicologists who study the effects of stress on individual species and natural communities are ideally situated to play a major role in this undertaking if more eco is put in ecotoxicology. The ultimate fate of individual species is extinction, but an intelligent species should be able to extend its time on the ecological stage of the evolutionary theater!

Acknowledgments. I am indebted to Darla Donald for typing the handwritten draft of this manuscript and for editorial assistance in preparing it for publication. Karen Cairns and Paul Ehrlich called useful references to my attention. Sean Richards and Mark Hanson, who co-chaired the SETAC special session honoring my life's work, kindly kept this travel-challenged, stay-at-home honoree informed of events and obtained permission for my brief comments read at the session to be included in this commentary. My graduate students were inspirational over the years - they kept my spirits up - as did my colleagues and staff for a period now over 60 years. Last, but far from least, I am eternally grateful to my mentor Ruth Patrick, for starting me on a career path that interests me even more than it did 60 years ago.

\section{LITERATURE CITED}

Cairns, J., Jr. 1949. The free-living Protozoa of the Conestoga Basin. Pages 1-110 in Biological Survey of the Conestoga Basin and Observations of the West Branch, Brandywine Creek, R. Patrick and H. R. Roberts, ed. Academy of Natural Sciences, Philadelphia, PA.

Cairns, J., Jr. 1956a. Effects of heat on fish. Industrial Wastes 1(5):180-183.

Cairns, J., Jr. 1956b. Effects of increased temperatures on aquatic organisms. Industrial Wastes 1(4):150-152.

Cairns, J., Jr. 1957. Environment and time in fish toxicity. Industrial Wastes 2(1):1-5.

Cairns, J., Jr. 1983. Are single species toxicity tests alone adequate for estimating environmental hazard? Hydrobiologia 100:47-57.

Cairns, J., Jr. and A. Scheier. 1957. The effects of periodic low oxygen upon the toxicity of various chemicals to fish. Purdue University Engineering Bulletin 94:166-176.

Cairns, J., Jr., A. Scheier and N. E. Hess. 1963. The effects of alkyl benzene sulfonate on aquatic organisms. Pages 43-54 in Proceedings, Fourth Annual Symposium on Industrial Waste Control. The Johns Hopkins University and the State of Maryland, Baltimore, MD.

Cairns, J., Jr., K. L. Dickson and A. Maki, ed. 1977. Estimating the Hazard of Chemical Substances to Aquatic Life. Spec. Tech. Publ. 657, American Society for Testing and Materials, Philadelphia, PA.

Cairns, J., Jr., G. P. Patil and W. E. Waters, ed. 1979. Environmental Biomonitoring, Assessment, Prediction, and Management - Certain Case Studies and Related Quantitative Issues. Statistical Ecology Volume S11. International Co-operative Publishing House, Fairland, MD.

Cairns, J., Jr., Chairman; M. Alexander, K. W. Cummins, W. T. Edmondson, C. R. Goldman, J. Harte, R. Hartung, A. R. Isensee, R. Levins, J. F. McCormick, T. J. Peterle and J. H. Zar. 1981. Testing for Effects of Chemicals on Ecosystems. National Academy Press, Washington, DC. 
Hart, W. B., P. Doudoroff and J. Greenbank. 1945. The Evaluation of the Toxicity of Industrial Wastes, Chemicals and Other Substances to Fresh Water Fishes. Waste Control Laboratory, Atlantic Refining Co., Philadelphia, PA.

Lakoff, G. 2008. The Political Mind. Penguin Group, New York, NY.

Patrick, R., J. Cairns, Jr. and S. S. Roback. 1967. An ecosystematic study of the fauna and flora of the Savannah River. Proceedings, Academy of Natural. Sciences, Philadelphia 118(5):109-407.

Following is a short piece that was read for me by Special Session co-chairs Mark Hanson and Sean Richards on November 18, 2008, at the SETAC Annual Meeting in Tampa, Florida.

\section{THE COMING REVOLUTION IN ECOTOXICOLOGY CAUSED BY RAPID CLIMATE CHANGE}

This old geezer in an assisted living facility at Warm Hearth Retirement Village in Blacksburg, Virginia, is delighted to share some thoughts on ecotoxicology. Before SETAC was founded, some doubts were voiced on the need for a transdisciplinary organization - the answer to those doubts is this lively professional organization. At present, climate change is occurring more rapidly and more drastically than even the Intergovernmental Panel on Climate Change (IPCC) had forecasted. Collapse and degradation of terrestrial and aquatic ecosystems require new information to prevent further damage; urgent needs include restoring damaged ecosystems and developing more robust predictive models. Visualize a future "Pellston Series" of SETAC books covering methodology and criteria to detect global ecological tipping points before they occur.

Most people fail to grasp the major ecological effects of $1^{\circ} \mathrm{C}$ increases in temperature. Individually, even a $6^{\circ} \mathrm{C}$ increase is no big deal, although Mark Lynas' 2008 book Six Degrees documents that even a $1^{\circ} \mathrm{C}$ increase can have dramatic ecological consequences. Humankind must learn that it can be blindsided by major loss of agricultural productivity, droughts and floods, severe damage to the biospheric life support system, and runaway release of presently inactive carbon into the atmosphere. These global climate positive feedback loops can still be diminished.

The assimilative capacity of the biosphere for carbon dioxide and other greenhouse gases has been exceeded for many years, and anthropogenic greenhouse gas emissions are still increasing markedly. This situation and greenhouse gas emissions positive feedback loops from stored $\mathrm{CO}_{2}$ and methane indicate an increasingly turbulent global climate. The biota is already adversely affected, and the situation will probably worsen short term. Many challenges will emerge for the rapidly developing field of ecotoxicology. I am confident that ecotoxicologists and SETAC will meet the challenge! Good luck on future endeavors and many thanks for honoring me with this Special Session! 